\title{
The application of a Poisson model to the annual distribution of daily mortality at six Montreal hospitals
}

\author{
J. P. ZWEIG AND J. Z. CSANK \\ From Sainte Anne's Hospital, Sainte Anne de Bellevue, Province of Quebec, Canada
}

SUMMARY The daily distributions of annual mortality for varying numbers of years between 1965 and 1975 were investigated in three geriatric hospitals and three general hospitals in the Montreal area. Nearly all the observed mortality distributions were found to mimic the classical Poisson distribution, with little departure. In two of the larger hospitals, the matching of the daily mortality distributions with their Poisson models met stringent statistical criteria. In one of them it was even possible to predict the expected mortality frequencies merely from a knowledge of the annual totals. The remaining four hospitals, which included the three geriatric institutions, also exhibited mortalities regarded as highly suggestive of Poisson distributions, although in one of the geriatric hospitals the mortality distribution tended to be somewhat erratic in this respect.

The observation by Zweig in March, 1973, that the daily pattern of mortality for the year 1972 at Ste. Anne's Hospital for disabled geriatric veterans could be modelled by the Poisson distribution for rare events led to further investigation. This study is a report of the findings of the annual distributions of daily mortality in six hospitals in Montreal.

The finding by Zweig arose during evaluation studies by Zweig and Csank $(1975 ; 1976)$ arising from the relocation of the general medical unit of Ste. Anne's Hospital in 1971. On the hypothesis that the annual distributions of daily mortality may follow a definite pattern, a series of frequency distributions was constructed year by year from 1967 to 1972 . The pattern of the mortality distributions was strikingly similar. Furthermore, the means and variances of these distributions were very nearly equal, which suggested that the observed frequencies might conform to Poisson-type distributions. Using the observed means as estimations for the $m$ values of the mathematical Poisson formulation

$$
\frac{\mathrm{e}^{-\mathrm{m}_{\mathrm{m}}}}{\mathrm{x} !}
$$

the expected theoretical frequencies were calculated, and the conformity to a Poisson model was acceptable. The continuation of this work in the years 1973 to 1975 strengthened support for the initial findings, and when all the data from 1967 to 1975 were pooled in a single distribution, the result also conformed to a theoretical Poisson distribution.

The appearance of the distribution of rare events was first noted by the distinguished French scientist S. D. Poisson (1837), but his discovery seems to have languished in obscurity for about 60 years. It was brought to light by Bortkewitsch (1898), who found that distribution of the number of deaths by horse kicks in the Prussian army per corps-year was closely matched by a theoretical Poisson distribution. Since then, the Poisson distribution has been shown to possess considerable versatility. Haight (1967) in his handbook notes applications of the Poisson distribution in many fields including accidents, medicine, biology, ecology, sociology, demography, queueing theory, etc.

Mosteller and Rourke (1973) discuss the general ideas underlying the distribution. They point out that the size and composition of the samples containing the event studied, though large, should be fairly constant. The interval within which the observation of the event is made, is fixed. Within the unit compounded of sample size and interval, the event studied should be found to occur rarely, at random, and independently of other similar events.

Research application of the Poisson model with a more direct bearing on the present investigation harks back to Bortkewitsch (1898), cited by Whitaker (1914), Thorndike (1926), and Mosteller and Rourke (1973). Mortara (1912) studied deaths 
from alcoholism and from smallpox in a number of districts in Italy. His findings suggested some conformity to a Poisson distribution. Whitaker (1914) extracted the ages at death of all persons over 70 whose obituaries appeared in The Times of London for three complete years from 1910 to 1912. The eight distributions which resulted, two of which were cited by Thorndike (1926) as good examples, appeared to agree with their corresponding theoretical Poisson distributions. Feller (1957), quoting data from another source, mentions the Poisson model for the number of centenarians who die each year. Vajani (1955) and Amato (1959) in Italy also conducted studies of mortality distributions of selected age groups. Vajani's research was carried out in the city of Milan for the combined years 1951 to 1953. Amato made a thorough investigation similar to Vajani's, but in the city of Catania, and for the combined years 1948 to 1955 . He was successful in showing that mortality distributions of selected age

Table 1 Hospitals in the study by size, services, and years of contributed data

\begin{tabular}{|c|c|c|c|}
\hline Hospital & $\begin{array}{l}\text { No. of beds } \\
\text { in } 1975\end{array}$ & Dominant services & $\begin{array}{l}\text { Contributed } \\
\text { data } \\
\text { (years) }\end{array}$ \\
\hline $\mathbf{A}$ & 1070 & Chronic, medical, psychiatric, & $1967-1975$ \\
\hline $\begin{array}{l}\mathbf{G} \\
\mathbf{J} \\
\mathbf{M} \\
\mathbf{R} \\
\mathbf{H}\end{array}$ & $\begin{array}{l}900 \\
685 \\
247 \\
241 \\
132\end{array}$ & $\begin{array}{l}\text { General, medical, surgical } \\
\text { General, medical, surgical } \\
\text { Chronic, medical, domiciliary } \\
\text { General, medical, surgical } \\
\text { Chronic, medical }\end{array}$ & $\begin{array}{l}1968-1972 \\
1965-1974 \\
1966-1972 \\
1966-1972 \\
1965-1973\end{array}$ \\
\hline
\end{tabular}

Source: Canadian Hospital Directory, 1975. Canadian Hospital Association, Toronto, Ontario, Volume 23, July, 1975. groups in Catania during those years followed a Poisson model. None of the research mentioned was directly related to hospitalised populations.

The finding at Ste. Anne's suggested that other hospitals might show similar mortality patterns. Accordingly, a study of hospitals in the Montreal area was launched in 1973. During two years a number of Montreal hospitals were approached on the arbitrary basis of availability, and daily mortality data over a range of years were requested.

\section{Methods}

The hospitals participating in this study varied in size; services offered; age, sex, and ethnic composition of clientele; and in other ways. Their size, dominant services, and the years for which they were able to contribute data, are shown in Table 1.

Three of these hospitals, $A, M$, and $H$, were geriatric institutions. Hospital A was a non-sectarian hospital for geriatric war veterans. Hospitals $\mathrm{M}$ and $\mathrm{H}$ had a geriatric, predominantly Jewish, clientele. The remaining three hospitals, G, J, and $R$, were general hospitals. If the years of contributed data are considered without regard to further distinctions, the entire study may be said to comprise a total of 47 samples, each of a hospital-year. Twenty-five of these samples were from geriatric populations and 22 were from general populations.

An annual distribution of the daily mortality in each hospital-year was constructed. These values of the daily deaths ranged from none to a maximum of eight deaths per hospital-day recorded once only.

Table 2 The observed annual distribution of daily mortality at six Montreal hospitals for various years from 1965 to 1975

\begin{tabular}{|c|c|c|c|c|c|c|c|c|c|c|c|c|c|c|c|c|c|c|c|c|}
\hline \multirow{2}{*}{$\begin{array}{l}\text { Daily } \\
\text { deaths }\end{array}$} & \multicolumn{9}{|c|}{ Hospital A } & & & & \multirow{2}{*}{$\begin{array}{l}\text { Daily } \\
\text { deaths }\end{array}$} & \multicolumn{7}{|c|}{ Hospital $R$} \\
\hline & 1967 & 1968 & 1969 & 1970 & 1971 & 1972 & 1973 & 1974 & 1975 & & & & & 1966 & 1967 & 1968 & 1969 & 1970 & 1971 & 1972 \\
\hline \multirow[t]{2}{*}{$\begin{array}{l}0 \\
1 \\
2 \\
3 \\
4\end{array}$} & $\begin{array}{r}239 \\
100 \\
24 \\
2 \\
0 \\
365 \\
\text { Hospit }\end{array}$ & $\begin{array}{r}229 \\
105 \\
27 \\
3 \\
2 \\
366 \\
\text { tal } H\end{array}$ & $\begin{array}{r}224 \\
117 \\
17 \\
6 \\
1 \\
365\end{array}$ & $\begin{array}{r}224 \\
106 \\
27 \\
8 \\
0 \\
365\end{array}$ & $\begin{array}{r}220 \\
113 \\
23 \\
8 \\
1 \\
365\end{array}$ & $\begin{array}{r}237 \\
99 \\
27 \\
3 \\
0 \\
366\end{array}$ & $\begin{array}{r}246 \\
93 \\
24 \\
2 \\
0 \\
365\end{array}$ & $\begin{array}{r}224 \\
111 \\
26 \\
4 \\
0 \\
365\end{array}$ & $\begin{array}{r}217 \\
112 \\
28 \\
7 \\
1 \\
365\end{array}$ & & & $\begin{array}{l}0 \\
1 \\
2 \\
3 \\
4\end{array}$ & & $\begin{array}{r}322 \\
40 \\
3 \\
0 \\
0 \\
365 \\
\text { Hospi }\end{array}$ & $\begin{array}{r}298 \\
59 \\
8 \\
0 \\
0 \\
365 \\
\text { tal } M\end{array}$ & $\begin{array}{r}276 \\
82 \\
8 \\
0 \\
0 \\
366\end{array}$ & $\begin{array}{r}271 \\
80 \\
13 \\
0 \\
1 \\
365\end{array}$ & $\begin{array}{r}255 \\
92 \\
16 \\
2 \\
0 \\
365\end{array}$ & $\begin{array}{r}254 \\
91 \\
19 \\
0 \\
1 \\
365\end{array}$ & $\begin{array}{r}257 \\
92 \\
17 \\
0 \\
0 \\
366\end{array}$ \\
\hline & 1965 & 1966 & 1967 & 1968 & 1969 & 1970 & 1971 & 1972 & 1973 & & & & & 1966 & 1967 & 1968 & 1969 & 1970 & 1971 & 1972 \\
\hline \multirow[t]{2}{*}{$\begin{array}{l}0 \\
1 \\
2 \\
3\end{array}$} & $\begin{array}{r}317 \\
43 \\
5 \\
0 \\
365 \\
\text { Hospit }\end{array}$ & $\begin{array}{r}330 \\
34 \\
1 \\
0 \\
365 \\
\text { tal } G\end{array}$ & $\begin{array}{r}329 \\
31 \\
5 \\
0 \\
365\end{array}$ & $\begin{array}{r}328 \\
32 \\
4 \\
2 \\
366\end{array}$ & $\begin{array}{r}330 \\
34 \\
1 \\
0 \\
365\end{array}$ & $\begin{array}{r}330 \\
35 \\
0 \\
0 \\
365\end{array}$ & $\begin{array}{r}324 \\
35 \\
6 \\
0 \\
365\end{array}$ & $\begin{array}{r}334 \\
31 \\
1 \\
0 \\
366\end{array}$ & $\begin{array}{r}323 \\
37 \\
5 \\
0 \\
365\end{array}$ & & Hospi & tal J & & $\begin{array}{r}312 \\
47 \\
6 \\
0 \\
365\end{array}$ & $\begin{array}{r}315 \\
49 \\
1 \\
0 \\
365\end{array}$ & $\begin{array}{r}318 \\
45 \\
3 \\
0 \\
366\end{array}$ & $\begin{array}{r}321 \\
38 \\
5 \\
1 \\
365\end{array}$ & $\begin{array}{r}311 \\
50 \\
4 \\
0 \\
365\end{array}$ & $\begin{array}{r}319 \\
43 \\
2 \\
1 \\
365\end{array}$ & $\begin{array}{r}320 \\
40 \\
5 \\
1 \\
366\end{array}$ \\
\hline & 1968 & 1969 & 1970 & 1971 & 1972 & & & & & deaths & 1965 & 1966 & 1967 & 1968 & 1969 & 1970 & 1971 & 1972 & 1973 & 1974 \\
\hline $\begin{array}{l}0 \\
1 \\
2 \\
3 \\
4 \\
5 \\
6 \\
7 \\
8\end{array}$ & $\begin{array}{r}42 \\
117 \\
89 \\
66 \\
37 \\
12 \\
2 \\
1 \\
0 \\
366\end{array}$ & $\begin{array}{r}41 \\
98 \\
108 \\
62 \\
31 \\
19 \\
4 \\
2 \\
0 \\
365\end{array}$ & $\begin{array}{r}57 \\
95 \\
98 \\
60 \\
35 \\
12 \\
5 \\
2 \\
1 \\
365\end{array}$ & $\begin{array}{r}49 \\
103 \\
101 \\
66 \\
32 \\
8 \\
5 \\
1 \\
0 \\
365\end{array}$ & $\begin{array}{r}43 \\
113 \\
99 \\
63 \\
28 \\
13 \\
5 \\
2 \\
0 \\
366\end{array}$ & & & & & $\begin{array}{l}0 \\
1 \\
2 \\
3 \\
4 \\
5 \\
6 \\
7\end{array}$ & $\begin{array}{r}144 \\
123 \\
71 \\
23 \\
3 \\
1 \\
0 \\
0 \\
365\end{array}$ & $\begin{array}{r}153 \\
138 \\
57 \\
9 \\
7 \\
1 \\
0 \\
0 \\
365\end{array}$ & $\begin{array}{r}137 \\
143 \\
62 \\
18 \\
5 \\
0 \\
0 \\
0 \\
365\end{array}$ & $\begin{array}{r}135 \\
126 \\
75 \\
24 \\
4 \\
2 \\
0 \\
0 \\
366\end{array}$ & $\begin{array}{r}101 \\
121 \\
97 \\
33 \\
9 \\
4 \\
0 \\
0 \\
365\end{array}$ & $\begin{array}{r}96 \\
114 \\
98 \\
34 \\
14 \\
8 \\
0 \\
1 \\
365\end{array}$ & $\begin{array}{r}90 \\
120 \\
89 \\
41 \\
19 \\
4 \\
2 \\
0 \\
365\end{array}$ & $\begin{array}{r}93 \\
115 \\
88 \\
45 \\
20 \\
3 \\
1 \\
1 \\
366\end{array}$ & $\begin{array}{r}67 \\
127 \\
84 \\
58 \\
21 \\
7 \\
0 \\
0 \\
365\end{array}$ & $\begin{array}{r}63 \\
118 \\
89 \\
60 \\
26 \\
9 \\
0 \\
0 \\
365\end{array}$ \\
\hline
\end{tabular}


All the 47 samples of the observed annual distributions of the daily mortality are presented in Table 2.

The mean, $m$, and the variance, $s^{2}$, were compared in each of these observed distributions. Using $m$ as the parameter mean estimated from each observed frequency distribution, a theoretical Poisson frequency distribution was constructed. These values were later verified by a method suggested by Waugh (1952) involving the use of tables. All frequencies obtained by the two methods agreed with negligible differences. $\chi^{2}$ tests of goodness-of-fit were conducted and probability values were determined.

This procedure was repeated with all the hospitals' data except those from hospital $J$, the final hospital considered in the study. In the case of hospital J, the observed frequencies per hospital-day could not be retrieved immediately, although the total mortality per hospital-year for a ten-year period was readily available. Since $m$ can be calculated from the totals alone, and since the Poisson model is fitted from these estimates, it was decided to construct the theoretical frequency distributions using the tables in Waugh (1952). The predicted frequency distributions were preserved by a member of the staff at Ste. Annes' Hospital. The actual data were retrieved about four months after the predictions had been made, and the observed distributions were compared with the predicted Poisson models.

In the next step, all the observed distributions were pooled for each hospital separately. The six means of these pooled distributions were determined and the corresponding Poisson models were constructed. The pooled observed data were compared with their corresponding Poisson models by means of $\chi^{2}$ tests of goodness-of-fit.

\section{Results}

The simple observation which led to the start of the investigation was the finding at Ste. Anne's that the mean of the observed daily mortality distribution for the year 1972, m, was 0.4426 and the variance, $s^{2}$, was 0.4447 . Similar comparisons followed in all the participating hospitals, and most of the differences were small enough to warrant an investigation into whether these could be approximated by a Poisson distribution. The comparison between the means and the variances of the 47 samples is summarised in Table 3.

The differences between the means and the variances $\left(m-s^{2}\right)$ are all small, ranging from -0.2085 to 0.1490 . Both of these extreme differences occur in hospital $G$, one of the larger hospitals. Most of the differences are small enough to be regarded as errors due to sampling variation. These occurrences were strongly indicative of conformity to the conditions for a Poisson model.

Accordingly, a Poisson model for each of the observed distributions was constructed, and the results of the $\chi^{2}$ tests are presented in Table 4 .

Table 4 Results of $\chi^{2}$ tests of goodness-of-fit of the annual mortality distributions to their corresponding models at six Montreal hospitals for various years from 1965-75

\begin{tabular}{|c|c|c|c|c|c|c|}
\hline \multirow[b]{3}{*}{ Year } & \multicolumn{6}{|c|}{ Hospitals } \\
\hline & $A$ & $G$ & $\boldsymbol{J}$ & $M$ & $R$ & $\boldsymbol{H}$ \\
\hline & $x^{2}$ & $x^{2}$ & $x^{2}$ & $x^{2}$ & $\chi^{2}$ & $x^{2}$ \\
\hline $\begin{array}{l}1975 \\
1974 \\
1973 \\
1972 \\
1971 \\
1970 \\
1969 \\
1968 \\
1967 \\
1966 \\
1965\end{array}$ & $\begin{array}{l}0.89 \\
0.28 \\
0.75 \\
0.67 \\
3.21 \\
1.70 \\
2.05 \\
0.20 \\
0.09 \\
- \\
-\end{array}$ & $\begin{array}{l}- \\
\overline{-} \\
3 \cdot 75 \\
1 \cdot 75 \\
2 \cdot 83 \\
4 \cdot 00 \\
7 \cdot 32 \\
- \\
-\end{array}$ & $\begin{array}{l}-7 \cdot 01 \\
4 \cdot 05 \\
2 \cdot 62 \\
1 \cdot 16 \\
6 \cdot 47 \\
3 \cdot 31 \\
1.47 \\
1 \cdot 06 \\
0.81 \\
2 \cdot 71\end{array}$ & $\begin{array}{l}- \\
- \\
2.56 \\
0.01 \\
0.01 \\
3.41 \\
0.02 \\
2.01 \\
0.87 \\
-\end{array}$ & $\begin{array}{l}- \\
\overline{-} \\
0.11 \\
0.07 \\
0.02 \\
0.04 \\
1.48 \\
0.33 \\
0.04 \\
-\end{array}$ & $\begin{array}{l}- \\
2.19 \\
0.25 \\
4.65^{*} \\
1.93 \\
0.29 \\
5.94^{*} \\
4.44^{*} \\
0.29 \\
0.82\end{array}$ \\
\hline $\begin{array}{l}\text { Total } \\
\chi^{20} 0.05\end{array}$ & $\begin{array}{r}9 \cdot 84 \\
22 \cdot 36\end{array}$ & $\begin{array}{l}\overline{19 \cdot 65} \\
37 \cdot 65\end{array}$ & $\begin{array}{l}\overline{25 \cdot 67} \\
48 \cdot 52(a)\end{array}$ & $\begin{array}{r}8 \cdot 89 \\
14 \cdot 07\end{array}$ & $\begin{array}{r}2 \cdot 09 \\
14 \cdot 07\end{array}$ & $\begin{array}{l}20 \cdot 80^{*} \\
16 \cdot 92\end{array}$ \\
\hline
\end{tabular}
(a) by interpolation

Forty-four of the $47 \chi^{2}$ values shown are associated with probability values greater than 0.05 . These probability values ranged from 0.07 to 0.93 . This

Table 3 Comparison between the means and variances of the annual distribution of daily mortality at six Montreal hospitals for various years from 1965 to 1975

\begin{tabular}{|c|c|c|c|c|c|c|c|c|c|c|c|c|}
\hline \multirow[b]{2}{*}{ Year } & \multicolumn{2}{|c|}{$\begin{array}{r}\text { Hospitals } \\
A\end{array}$} & \multicolumn{2}{|c|}{$\boldsymbol{G}$} & \multicolumn{2}{|c|}{$\boldsymbol{J}$} & \multicolumn{2}{|c|}{$M$} & \multicolumn{2}{|c|}{$\boldsymbol{R}$} & \multicolumn{2}{|c|}{$\boldsymbol{H}$} \\
\hline & $m$ & $s^{2}$ & $\bar{m}$ & $s^{2}$ & $\bar{m}$ & $s^{2}$ & $m$ & $s^{2}$ & $m$ & $s^{2}$ & $m$ & $s^{2}$ \\
\hline $\begin{array}{l}1975 \\
1974 \\
1973 \\
1972 \\
1971 \\
1970 \\
1969 \\
1968 \\
1967 \\
1966 \\
1965\end{array}$ & $\begin{array}{l}0 \cdot 5287 \\
0.4794 \\
0 \cdot 4027 \\
0 \cdot 4426 \\
0 \cdot 5123 \\
0 \cdot 5041 \\
0 \cdot 4739 \\
0 \cdot 4808 \\
0 \cdot 4219\end{array}$ & $\begin{array}{l}0 \cdot 5521 \\
0.4591 \\
0 \cdot 4061 \\
0 \cdot 4447 \\
0 \cdot 5418 \\
0 \cdot 5309 \\
0 \cdot 4754 \\
0 \cdot 5134 \\
0 \cdot 4094\end{array}$ & $\begin{array}{r}1.9699 \\
1.9397 \\
1.9808 \\
2.0739 \\
1.9672\end{array}$ & $\begin{array}{l}1 \cdot 9362 \\
1 \cdot 8371 \\
2 \cdot 1893 \\
2 \cdot 0086 \\
1 \cdot 8182\end{array}$ & $\begin{array}{l}1 \cdot 7123 \\
1 \cdot 6191 \\
1 \cdot 4590 \\
1.4493 \\
1 \cdot 4109 \\
1 \cdot 2876 \\
1.0218 \\
0.9342 \\
0.8547 \\
0.9616\end{array}$ & $\begin{array}{r}1 \cdot 6067 \\
1 \cdot 5060 \\
1 \cdot 5696 \\
1 \cdot 5229 \\
1 \cdot 5341 \\
1 \cdot 2188 \\
1 \cdot 0243 \\
0 \cdot 8639 \\
0 \cdot 8718 \\
0 \cdot 9602\end{array}$ & $\begin{array}{l}0 \cdot 1448 \\
0 \cdot 1370 \\
0 \cdot 1589 \\
0 \cdot 1397 \\
0 \cdot 1393 \\
0 \cdot 1397 \\
0 \cdot 1616\end{array}$ & $\begin{array}{l}0 \cdot 1680 \\
0 \cdot 1460 \\
0 \cdot 1560 \\
0 \cdot 1645 \\
0 \cdot 1367 \\
0 \cdot 1260 \\
0 \cdot 1689\end{array}$ & $\begin{array}{l}0.3443 \\
0.3644 \\
0 \cdot 3562 \\
0 \cdot 3014 \\
0 \cdot 2678 \\
0 \cdot 2055 \\
0 \cdot 1260\end{array}$ & $\begin{array}{l}0.3195 \\
0 \cdot 3696 \\
0 \cdot 3508 \\
0 \cdot 3155 \\
0 \cdot 2404 \\
0 \cdot 2076 \\
0.1269\end{array}$ & $\begin{array}{l}0 \cdot 1288 \\
0 \cdot 0902 \\
0 \cdot 1288 \\
0 \cdot 0959 \\
0.0986 \\
0 \cdot 1257 \\
0 \cdot 1123 \\
0 \cdot 0986 \\
0 \cdot 1452\end{array}$ & $\begin{array}{l}0.1400 \\
0.0877 \\
0.1455 \\
0.0869 \\
0.0946 \\
0.1650 \\
0.1275 \\
0.0946 \\
0.1519\end{array}$ \\
\hline
\end{tabular}


signifies that, in those cases, the match of the observed distributions to their expected Poisson distributions ranged from acceptable to exceptionally good.

Three of the probability values determined were less than $\mathbf{0} \cdot 05$. All of these came from hospital $\mathrm{H}$, the smallest hospital, with only 132 beds.

In hospital $\mathbf{J}$, in which the Poisson models were constructed before the observed data were retrieved, nine of the ten hospital-years provided distributions which met all the conditions for a $\chi^{2}$ test.

In the overall picture, $93 \%$ of the $\chi^{2}$ values shown in Table 4 are non-significant, $78 \%$ having probabilities greater than $P=0.19$ and $55 \%$ having probabilities greater than $P=0.49$. If the larger hospitals only, $\mathbf{G}$ and $\mathrm{J}$, are considered, the picture is even better.

Because of its additive nature, the $\chi^{2}$ values from a number of independent distributions may be summed. All the summed $\chi^{2}$ values, with the exception of the total for hospital $\mathrm{H}$, were non-significant, and much below the tabular values of $\chi^{2} 0.05$ shown at the bottom of Table 4. This means that the total divergence of observed from expected values in each of those hospitals for all the years in which they were involved is quite small. Excluding hospital $\mathbf{H}$, the Poisson model appears to be appropriate for the data regarded as a whole.

As a further illustration of the appropriateness of the Poisson model, all the data contributed by each hospital were pooled to form six global distributions. The results of applying the $\chi^{2}$ tests of goodness-of-fit are shown in Table 5.

Table 5 Results of the $\chi^{2}$ tests of goodness-of-fit of the pooled annual distributions of mortality and the corresponding Poisson models at six Montreal hospitals for the combined number of years indicated

\begin{tabular}{lcllrl}
\hline Hospital & No. of years & $m$ & $s^{2}$ & \multicolumn{1}{l}{$\chi^{2}$} & $p$ \\
\hline A & 9 & 0.4718 & 0.4819 & 1.85 & 0.61 \\
G & 5 & 1.9863 & 1.9556 & 3.45 & 0.75 \\
J & 10 & 1.2711 & 1.3499 & 12.89 & $0.03 *$ \\
M & 7 & 0.1458 & 0.1521 & 1.25 & 0.27 \\
R & 7 & 0.2807 & 0.2819 & 2.36 & 0.31 \\
H & 9 & 0.1138 & 0.1216 & 6.70 & $0.01^{*}$ \\
\hline
\end{tabular}

*Significant at $\mathrm{P}<0.05$

Four of the six $\chi^{2}$ values were found to be nonsignificant, the lowest probability being $0 \cdot 27$. Only in hospitals $\mathbf{H}$ and $\mathrm{J}$ were the probabilities less than 0.05 . The means for hospital $J$, shown in Table 3, suggested that the mortality means from 1970 to 1974 are greater, and resemble each other more than they resemble the mortality means from 1965 to 1969 . These findings suggest some change in hospital J which caused mortality to differ after 1969.

In order to pursue this further, the pooled data of hospital $J$ were separated into two parts: $J_{1}$ from 1965 to 1969 , and $J_{2}$ from 1970 to 1975 . The $\chi^{2}$ for the first period was $2.96(P=0.57)$, and for the second period it was $4 \cdot 26(\mathrm{P}=0 \cdot 51)$. It appears that whatever happened at hospital J before 1970 had tended to change the character of the mortality distribution after 1970.

\section{Discussion}

Haight (1967) states that it would also be fair to claim that the Poisson distribution is second in importance to the normal, whether regarded from the point of view of abstract theory or judged by the breadth of its application'.

All that will be attempted here is to show, firstly, that the mathematical Poisson distribution has been appropriately used, and, secondly, that the annual distribution of the day-to-day mortality at the hospitals which participated in this study can be adequately described by this classical model.

With regard to constancy of sample size and of the interval studied, every hospital may be regarded as a microcosm whose size is fixed by its bed capacity. Under ordinary circumstances, the pressure for admission to urban hospitals is usually sufficient to ensure that a vacated bed is likely to be reoccupied within a day or so. Consequently, whether the beds are vacated by discharge of patients or by mortality, the number of new admissions ensures that the total number of beds occupied on any day of the year will be more or less the same.

If the pattern of daily mortality is a Poisson distribution, then the bed vacancies attributable to deaths in the hospital must also follow a Poisson distribution. While the number of bed vacancies attributable to daily deaths may not be a great fraction of the total, the role played by this component could well be a subject of interest for hospital administrators concerned with the problem of providing accommodation for new admissions.

The constancy of sample composition is another matter. No attempt was made to control for age, sex, or ethnic composition. Hospitals in the Montreal area cater for a cosmopolitan ethnic mix of all ages and both sexes. There is a growing tendency towards non-sectarianism in all Montreal hospitals because of public funding. If differentiation by age, sex, or ethnic composition has a bearing on mortality distributions, then it can be said that these Montreal hospitals tended to display the Poisson phenomena in spite of those conditions.

It is more difficult to say that the sample size, taken over a hospital-year with each hospital considered separately, was large enough in every case. Hospitals $A, G$, and J, with 1070,900 , and 685 beds respectively, 
seem to have provided the best examples of Poissontype mortality distributions. Hospitals $\mathbf{M}, \mathbf{R}$, and $\mathbf{H}$, with 247,241 , and 132 beds, generated distributions which may be regarded only as suggestive of a Poisson model. Nevertheless, even if the Poisson phenomena can be established in large hospitals only, that fact should be remarkable enough.

The event studied is the discrete distribution of the random variable 'number of deaths per day'. The question may be raised whether this particular variable may be considered to be a rare event in a hospital-day. In $\mathrm{m}=\mathrm{nP}$, if $\mathrm{n}$ is the number of times the observation is made (which in this case equals the number of days in each year), and $m$ is the average number of deaths per hospital-day, then $\frac{m}{n}$ can provide some idea of the size of $P$ in the hospitals studied. In Table 3, the smallest value of $m$ is 0.0902 (in hospital H) and the largest value of $\mathrm{m}$ is 2.0739 (in hospital G), from which the value of $P$ can be determined to be of the order of from 0.00025 to 0.00568 . These probabilities are sufficiently small to describe the occurrence of the average number of deaths per hospital-day in any hospital-day picked at random as a rare event. On this point, Hoel (1966) states that the Poisson approximation should be sufficiently accurate for most applicatonis if $n$ is at least 100 and $P$ is at most 0.05 .

The question could also be raised that these probabilities are not constant, due to seasonal or epidemic peaks, but Haight (1967) states that 'The Poisson limit (of the binomial distribution) applied also in cases where the probability of success may vary from trial to trial'.

Finally, there appears to be no general way in which the event 'number of deaths' on a particular hospital-day could be related to another such event on another hospital-day of the year, although isolated cases of such relationship are conceivable. In general, the rare events considered here may be said to occur at random and independently, and therefore also meet that criterion of the Poisson model.

The distinguishing mathematical property of the Poisson, and the one which opened this study in the first instance, is the identity of the means and variances of Poisson distributions. The results in Table 3 show mainly small differences, and in some cases very small differences, between the means and variances.

Hoel (1966) suggests that when using the $\chi^{2}$ test of significance there be at least five categories, and that the least number of expected cases in each category be no fewer than five. Strictly speaking, only hospitals $\mathbf{G}$ and $\mathbf{J}$ generated distributions which met these criteria. In the smaller hospitals, the expected mortality distributions often did not reach more than the three or four deaths per day category, and even then at times when the expected category frequency was fewer than five. Consequently, though nearly all the $\chi^{2}$ values obtained from the goodnessof-fit tests in the smaller hospitals were also non-significant, the matching of their mortality distributions with their Poisson models is regarded merely as suggestive of agreement. Of course, if the criteria used were less exacting, say a minimum of three categories grouped as suggested by Cochran (1954) so that the minimum expectation is at least one in the ultimate category, then nearly all the observed mortality distributions may be satisfactorily fitted by a Poisson model. At the very least, these distributions may be said to have heuristic value.

Omitting these smaller distributions still leaves 14 hospital-years which met all restrictions and in which the probability ranged from $0 \cdot 17$ to $0 \cdot 88$. This still gives strong support to the contention that daily mortality in certain hospitals follows a Poisson distribution.

There were three $\chi^{2}$ values with a probability $P<0.05$. These occurred in hospital $\mathrm{H}$, the smallest participant. Hospital $\mathbf{H}$ differs from the other hospitals in a number of ways. It caters to chronic medical geriatric patients and it tends to admit terminal cases. These facts, coupled with small size, may cause the mortality pattern in certain years to become biased, leading to departures from a Poisson model.

In general, the data of Table 4 may be said to provide a high degree of support for the view that the mortality distributions in the hospitals under consideration conform to a Poisson model.

The results of pooling the separate data of the participating hospitals, which appear in Table 5, provide further support for the central notion which governs this study, even though two of the six $\chi^{2}$ values gave a probability less than 0.05 . The case of hospital $\mathrm{H}$ has been explained above. The case of hospital $\mathbf{J}$ was more puzzling because none of the ten component distributions showed significant departures from their best fitting Poisson expectation. Yet the pooled data appeared to be inconsistent with the notion of a Poisson process.

When the data for hospital $\mathbf{J}$ were reorganised into two periods, $J_{1}$ and $J_{2}$, so as to reflect the similarities of the periods $1965-1969$ and 1970-1974 respectively, the pooled distributions for each of the periods $J_{1}$ and $J_{2}$ both conformed to the Poisson models. It was discovered that hospital $\mathrm{J}$ had undergone a programme of expansion which increased the numbers of beds occupied and extended its services. The construction of new quarters and the extension of services were completed in 1969. When the hospital data were separated at a point after the change was completed, the new value of $m$ 
which emerged in $\mathbf{J}_{2}$ caused the appearance of a new Poisson process. It may be possible that the Poisson model can be used to detect some kinds of changes in hospital mortality distributions from year to year.

\section{Conclusion}

We believe that the daily mortality in each of the six hospitals in this study demonstrates a tendency to conform to the Poisson distribution. Hospital administrators, archivists, and epidemiologists may be interested in extending the study to find out whether this is a generalisation which can be upheld elsewhere.

Some uses of this application of the Poisson distribution may be suggested. It could be used to serve as a predictor of annual mortality distributions in hospitals. It could be used in connection with other factors in estimating the provision of hospital beds for new admissions. The finding, if regular, may have some epidemiological significance in helping to locate changes in annual mortality distributions. Finally, those interested in the theory of queues may be able to deal with this finding as an example of a Poisson process governing a service at termination points.

We thank Dr. J. Buchbinder, Jewish General Hospital; Dr. D. J. McClure, Montreal General Hospital; Dr. E. Nayar, Reddy Memorial Hospital; Dr. G. Rosenberg, Maimonides Hospital and Home for Aged; Mr. M. Simak, Jewish Hospital of Hope; Mr. T. Speevak, Bell Canada; Miss Vicki Cowan, Montreal; Dr. L. G. Leblanc, Dr. G. H. Turcot, Dr. G. W. Halpenny, Dr. R. E. G. Place, Mr. R. Gurekas, Mr. M. Johnson, Mr. J. Lebrun, Mrs. Ginette Pagé, Miss Nicole Brault, and Dr. F. W. Lundell.

This study is part of research projects Nos. 6-73 of the Department of Veterans' Affairs, Government of Canada, and No. 5852 of the Medical Research Council of Canada.

Reprints from J. Z. Csank, Director of Psychiatric and Psychological Research, Sainte Anne's Hospital, 305, St. Pierre Street, Sainte Anne de Bellevue, Quebec, Canada H9X 1 Y9.

\section{References}

Amato, V. (1959). L'esponenziale di Poisson e la distribuzione del numero dei morti per giorno. Statistica, (Bologna), 19, 20-59.

Bortkewitsch, L. von (1898). Das Gesetz der Kleinen Zahlen. B. G. Teubner: Leipzig. (Also in Mosteller, F., and Rourke, R. E. K., op cit., p. 126; Thorndike, F., op cit., p. 622; and Whitaker, L., op cit., p. 53).

Cochran, W. G. (1954). Some methods for strengthening the common $\chi^{2}$ tests. Biometrics, 10, 417-451.

Feller, W. (1957). An Introduction to Probability Theory and its Application, Volume 1, p. 113. John Wiley and Sons: New York.

Haight, F. A. (1967). Handbook of the Poisson Distribution, p. 23; pp. 100-107; p.115. John Wiley and Sons: New York.

Hoel, P. G. (1966). Introduction to Mathematical Statistics, p. 247. John Wiley and Sons: New York.

Mortara, G. (1912). Sulle variaziani di frequenza di alcuni fenomeni demografici rari. Annali di Statistica, Serie V, IV, 5-81. (Also in Whitaker, L., op cit., p. 67; and Amato, V., op cit., p. 27).

Mosteller, F., and Rourke, R. E. K. (1973). Sturdy Statistics, pp. 125-140. Addison-Wesley: Reading, Massachusetts.

Poisson, S. D. (1837). Recherches sur la Probabilité des Jugements en Matière Criminelle et en Matière Civile, Précédés des Règles Générales du Calcul des Probabilités, pp. 205-207. Bachelier ImprimeurLibraire: Paris.

Thorndike, F. (1926). Applications of Poisson's probability summation. Bell System Technical Journal, 5, 604-624.

Vajani, L. (1955). Indagine su una distribuzione del numero dei morti per giorno nella età senili. Revista Italiana di Economia, Demografia e Statistica, 9, Nos. 1 and 2. (Also in Amato, V., op cit., pp. 35-36).

Waugh, A. E. (1952). Statistical Tables and Problems, p. 74. McGraw-Hill: New York.

Whitaker, L. (1914). On the Poisson law of small numbers. Biometrika, 10, 36-71.

Zweig, J. P., and Csank, J. Z. (1975). Effects of relocation on chronically ill patients of a medical unit: Mortality rates. Journal of the American Geriatrics Society, 23, 132-136.

Zweig, J. P., and Csank, J. Z. (1976). Mortality fluctuations among chronically ill medical geriatric patients as an indicator of stress before and after relocation. Journal of the American Geriatrics Society, 24, 264-277. 